\title{
Whole genome gene expression changes and hematological effects of rikkunshito in patients with advanced non-small cell lung cancer receiving first line chemotherapy
}

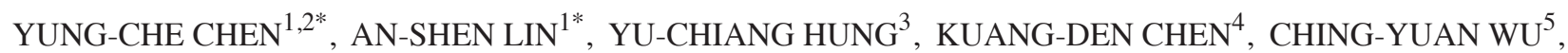 \\ CHIEN-HAO LIE ${ }^{1}$, CHANG-CHUN HSIAO ${ }^{2}$, CHUNG-JEN CHEN ${ }^{6}$, SHIH-FENG LIU ${ }^{1}$, WEN-FENG FANG ${ }^{1,7}$, \\ JEN-CHIEH CHANG ${ }^{2}$, TING-YA WANG ${ }^{1}$, YI-HSI WANG ${ }^{1}$, YU-HSIU CHUNG ${ }^{1}$, TUNG-YING CHAO ${ }^{1}$, \\ SUM-YEE LEUNG ${ }^{1}$, MAO-CHANG SU ${ }^{1,7}$ and MENG-CHIH LIN ${ }^{1}$
}

\footnotetext{
${ }^{1}$ Division of Pulmonary and Critical Care Medicine; ${ }^{2}$ Division of Rheumatology; ${ }^{3}$ Department of Chinese Medicine and School of Traditional Chinese Medicine; ${ }^{4}$ Center for Translational Research in Biomedical Science, Kaohsiung Chang Gung Memorial Hospital and Chang Gung University College of Medicine, Kaohsiung 83301; ${ }^{5}$ Department of Chinese Medicine, Chiayi Chang Gung Memorial Hospital, Chiayi 61361; ${ }^{6}$ Graduate Institute of Clinical Medical Sciences, Chang Gung University College of Medicine, Kaohsiung 83301; ${ }^{7}$ Department of Respiratory Care, Chang Gung University of Technology, Chiayi 61363, Taiwan R.O.C.
}

Received May 30, 2016; Accepted March 24, 2017

DOI: $10.3892 /$ etm.2017.4773

\begin{abstract}
It has been demonstrated that the traditional Chinese medicine rikkunshito, ameliorates anorexia in several types of human cancer and attenuates lung injury by inhibiting neutrophil infiltration. The current study investigated the clinical and hematological effects of rikkunshito and its underlying mechanisms of action in the treatment of advanced non-small cell lung cancer (NSCLC). The Illumina microarray BeadChip was used to analyze the whole-genome expression profiles of peripheral blood mononuclear cells in 17 patients with advanced NSCLC. These patients were randomized to receive combination chemotherapy (cisplatin and gemcitabine) with ( $n=9$, CTH+R group) or without ( $n=8$, CTH group) rikkunshito. The primary endpoint was the treatment response and the categories of the scales of anorexia, nausea, vomiting and fatigue; secondary endpoints included the hematological effect and whole genome gene expression changes. The results of the current study indicated that there were no significant differences in clinical outcomes, including treatment response and toxicity events, between the two groups. Median one-year
\end{abstract}

Correspondence to: Dr Meng-Chih Lin, Division of Pulmonary and Critical Care Medicine, Kaohsiung Chang Gung Memorial Hospital and Chang Gung University College of Medicine, 123 Ta-Pei Road, Niao-Sung, Kaohsiung 83301, Taiwan R.O.C.

E-mail: linmengchih@hotmail.com

${ }^{*}$ Contributed equally

Key words: rikkunshito, non-small cell lung cancer, chemotherapy, microarray gene expression, neutropenia overall survival (OS) was 12 months in the CTH group and 11 months in the $\mathrm{CTH}+\mathrm{R}$ group ( $\mathrm{P}=0.058$ by log-rank test), while old age ( $>60$ years old) was the only independent factor associated with one-year OS (hazard ratio 1.095, 95\% confidence interval, 1.09-1.189, $\mathrm{P}=0.030$ ). Patients in the $\mathrm{CTH}+\mathrm{R}$ group experienced significantly greater maximum decreases in both white cell count $(\mathrm{P}=0.034)$ and absolute neutrophil count $(\mathrm{P}=0.030)$ from the baseline. A total of 111 genes associated with neutrophil apoptosis, the cell-killing ability of neutrophils, natural killer cell activation and B cell proliferation were up-regulated following rikkunshito treatment. A total of 48 genes associated with neutrophil migration, coagulation, thrombosis and type I interferon signaling were down-regulated following rikkunshito treatment. Rikkunshito may therefore affect the blood neutrophil count when used with combination chemotherapy in patients with NSCLC, potentially by down-regulating prostaglandin-endoperoxidase synthase 1, MPL, AMICA1 and junctional adhesion molecule 3 , while up-regulating elastase, neutrophil expressed, proteinase 3, cathepsin $\mathrm{G}$ and cluster of differentiation 24 .

\section{Introduction}

Lung cancer is a major cause of mortality worldwide, with more than 1.8 million new cases and almost 1.6 million deaths estimated in 2012 (1). The age-standardized incidence rate of lung cancer was $64.8 / 10^{5}$ for men and $48.6 / 10^{5}$ for women in the USA from 2011 to 2014 , while the age-standardized mortality rate was $57.8 / 10^{5}$ for men and $37 / 10^{5}$ for women $(1,2)$. The incidence rate of lung cancer in China was $63.9 / 10^{5}$ for men and $31.9 / 10^{5}$ for women in 2011 , while the mortality rate was $50.9 / 10^{5}$ for men and $23.8 / 10^{5}$ for women (3). Non-small cell lung cancer (NSCLC) accounts for $\geq 80 \%$ of all lung tumors, and $\sim 66 \%$ of patients initially present with an inoperable form 
of the disease (4). Treatment with cisplatin (CDDP)-based chemotherapy $(\mathrm{CTH})$ leads to a $10 \%$ increase in the 1-year survival rate and increases median survival time by 2 months. It is currently considered the first line treatment for patients with advanced NSCLC who lack a sensitizing mutation of epidermal growth factor receptor (EGFR) (5). The addition of a second drug [either gemcitabine (GEM), vinorelbine, docetaxel or paclitaxel) generates only small improvements in tumor responses and survival rates (6). Recently it was determined that the addition of bevacizumab, a monoclonal antibody for vascular endothelial growth factor, increased the survival and response rates in patients with advanced NSCLC receiving CTH (7). However, bevacizumab is expensive and thus may not be developed for wider use (7). CTH-induced neutropenia is independently associated with increased survival rates of patients with advanced NSCLC, possibly due to a reduction in tumor-related leukocytosis (8-11). Neutropenia occurring in patients with early stage breast cancer is also an independent predictor of increased survival (12). The mechanisms that the body uses to counter $\mathrm{CTH}$-induced neutropenia remain unknown and may be caused by a combination of factors, such as variations in drug metabolism.

Rikkunshito (also known as TJ-43 or Liu-Jun-Zi-Tang) is a common prescription of traditional Chinese and Japanese Kampo medicines consisting of 8 herbs (Atractylodis lanceae rhizoma, Ginseng radix, Pinelliae tuber, Hoelen, Zizyphi fructus, Aurantii nobilis pericarpium, Glycyrrhizae radix and Zingiberis rhizoma) and is commonly used to treat gastrointestinal diseases (13). It has been demonstrated that rikkunshito ameliorates CDDP-induced anorexia, improves patient quality of life (14) and relieves functional dyspepsia via antagonistic action of the 5-Hydroxytryptamine (HT) $2 \mathrm{~B} / 2 \mathrm{C} / 3$ receptor pathway (15-17). Rikkunshito has been used to ameliorate anorexic symptoms, such as dysmotility-like dyspepsia, postprandial fullness, early satiety and epigastric burning, in cancer cachexia-anorexia syndrome, particularly in patients with colon and breast cancer $(18,19)$. Intervention with herbs used in traditional Chinese medicine herbs may increase efficacy and reduce toxicity when used in combination with EGFR-tyrosine kinase inhibitor to treat advanced NSCLC (20). Thus, it was hypothesized that rikkunshito may be effective at increasing patient responses to treatment and decreasing the side effects of combination $\mathrm{CTH}$ in patients with advanced stage NSCLC. In the present study, a randomized double blind clinical trial was conducted to determine whether rikkunshito may be appropriate to use as an adjuvant treatment during chemotherapy for patients with NSCLC. Furthermore, a microarray genomic expression method was used to identify the molecular processes involved in CTH and the whether rikkunshito induced any changes in peripheral blood mononuclear cells (PBMC).

\section{Patients and methods}

Patients. The study participants were recruited from the pulmonary clinics of Kaohsiung Chung Gung Memorial Hospital (Kaohsiung, Taiwan) between August 2007 and January 2009. A total of 17 patients were enrolled in the current study. Patients were aged $\geq 20$ years with histologically confirmed, newly diagnosed, untreated stage IIIB or IV NSCLC based on the international staging system for lung cancer $(21), \geq 1$ measurable (uni-dimensional) lesion with a diameter $\geq 10 \mathrm{~mm}$ using spiral computerized tomography and an ECOG performance status (22) of 0,1 or 2 . Exclusion criteria included hypersensitivity to any herbal drug, receipt of concurrent immunotherapy or radiotherapy, uncontrolled medical illness and history of other malignancies within the last 5 years. The study protocol followed the guidelines of the Declaration of Helsinki and was approved by the institutional review boards of Kaohsiung Chang Gung Memorial Hospital (certificate no. 96-0363B). All patients provided written informed consent for inclusion in the current study.

Treatment plan. All enrolled patients were randomly assigned into one of two groups: A CTH+R group $(n=9)$ or a $\mathrm{CTH}$ group $(n=8)$. All patients received combination $\mathrm{CTH}$ with CDDP (Platinex ${ }^{\circledR}$; Dabur India Limited, New Delhi, India; mean dose $60 \mathrm{mg} / \mathrm{m}^{2}$ ) on day 1 plus GEM (GEMZAR ${ }^{\circledR}$; mean dose $1000 \mathrm{mg} / \mathrm{m}^{2}$; Lilly, Indianapolis, IN, USA) on day 1, 8 and 15 of a 28-day cycle, as well as dry powder placebo (corn starch; Chuang Song Zong Pharmaceutical Co., Ltd., Kaohsiung, Taiwan) $30 \mathrm{~g}$ administered orally daily (CTH group), or combination chemotherapy plus rikkunshito $30 \mathrm{~g}$ administered orally daily ( $\mathrm{CTH}+\mathrm{R}$ group). The powder extract of rikkunshito was a mixture of $5.00 \mathrm{~g}$ ginseng radix, $5.00 \mathrm{~g}$ atractylodis rhizoma, $5.00 \mathrm{~g}$ hoelen, $5.00 \mathrm{~g}$ pinelliae tuber, $2.50 \mathrm{~g}$ glycyrrhizae radix, $2.50 \mathrm{~g}$ auranti nobilis pericarpium, $2.50 \mathrm{~g}$ gingiberis rhizoma, $2.50 \mathrm{~g}$ zizyphi Fructus and $7.80 \mathrm{~g}$ starch for each $100.00 \mathrm{~g}$ power with a crude drug: extract ratio of 30.00:7.80 (LIOW JIUN TZYY TANG extract powder; no. 2088; Chuang Song Zong pharmaceutical Co., Ltd.). Treatment was planned for a maximum of six cycles unless discontinued due to disease progression, unacceptable toxicity, physician or patient decision, requirement for palliative radiotherapy or patient mortality. All patients received the 5-HT3 receptor antagonist granisetron (Kytril ${ }^{\circledR} ; 2$ mg; TTY Biopharm, Taipei, Taiwan), metoclopramide (Promeran ${ }^{\circledR}$; 7.68 mg; Standard Chem. \& Pharm. Co., Ltd., Tainan, Taiwan) and dexamethasone (Methasone ${ }^{\circledR} ; 10 \mathrm{mg}$; Taiwan Veterans Pharm. Co., Ltd., Chung-Li, Taiwan) as anti-emetic agents in each combination $\mathrm{CTH}$ regimen. Following baseline evaluation, tumor status was assessed following last course of chemotherapy, according to the Response Evaluation Criteria in Solid Tumors (23). Leukocyte, hemoglobin levels and platelet counts as well as events of subjective toxicity were recorded on day 1,8 and 15 in each treatment course. Maximum changes in the hematological parameters were defined as the value prior to treatment minus the mean lowest value for each treatment course. Toxicity was graded prior to each treatment cycle using the National Cancer Institute Common Toxicity Criteria for Adverse Events version 3.0 (24). Overall survival (OS) was defined as time from enrollment until mortality from any cause within a 1- to 3-year observation period. Progression-free survival (PFS) was defined as the time from date of randomization to the date of first observation of progression [defined as $\geq 20 \%$ increase in the sum of the largest diameter of target lesions (23)] or mortality due to any cause. The primary endpoint was the treatment response and the categories of the scales of anorexia, nausea, and vomiting [based on evaluation of event frequency and clinical impact (24)] during the 
Table I. Comparison of the baseline characteristics of $\mathrm{CTH}$ and the CTH+R group.

\begin{tabular}{|c|c|c|c|}
\hline Characteristic & CTH group, $n=8$ & $\mathrm{CTH}+\mathrm{R}$ group, $\mathrm{n}=9$ & P-value \\
\hline Age, years & $56.7 \pm 15$ & $67.5 \pm 8.7$ & 0.135 \\
\hline Male, n (\%) & $6(75)$ & $7(77.8)$ & 0.893 \\
\hline TNM tumor stage, $\mathrm{n}(\%)$ & & & 0.086 \\
\hline $\mathrm{IIIb}$ & $6(75)$ & $3(33.3)$ & \\
\hline IV & $2(25)$ & $6(66.7)$ & \\
\hline Histology, n (\%) & & & 0.893 \\
\hline Adenocarcinoma & $6(75)$ & $7(77.8)$ & \\
\hline Squamous cell carcinoma & $2(25)$ & $2(22.2)$ & \\
\hline ECOG performance status & & & 0.363 \\
\hline 0 & $0(0)$ & $2(22.2)$ & \\
\hline 1 & $7(87.5)$ & $6(66.7)$ & \\
\hline 2 & $1(12.5)$ & $1(11.1)$ & \\
\hline \multicolumn{4}{|l|}{ Co-morbidity, n (\%) } \\
\hline Diabetes mellitus & $1(12.5)$ & $2(22.2)$ & 0.600 \\
\hline Hypertension & $4(50)$ & $4(44.4)$ & 0.819 \\
\hline Chronic bronchitis & $5(62.5)$ & $3(33.3)$ & 0.229 \\
\hline Chronic hepatitis & $1(12.5)$ & $1(11.1)$ & 0.929 \\
\hline Chronic kidney disease & $0(0)$ & $1(11.1)$ & 0.331 \\
\hline Congestive heart failure & $1(12.5)$ & $0(0)$ & 0.274 \\
\hline Smoking history, n (\%) & & & 0.959 \\
\hline Never & $3(37.5)$ & $4(44.4)$ & \\
\hline Former & $4(50)$ & $4(44.4)$ & \\
\hline Current & $1(12.5)$ & $1(11.1)$ & \\
\hline \multicolumn{4}{|c|}{ Mean dosage of chemotherapy agent $\left(\mathrm{mg} / \mathrm{m}^{2}\right)$} \\
\hline Cisplatin & $67.4 \pm 6.2$ & $69.2 \pm 6.9$ & 0.590 \\
\hline Gemcitabine & $973.1 \pm 65.1$ & $968.7 \pm 82.4$ & 0.782 \\
\hline
\end{tabular}

All data are presented as the mean \pm standard deviation unless otherwise specified. $\mathrm{CTH}$, combination chemotherapy group; CTH+R group, combination chemotherapy plus rikkunshito group.

treatment course (duration, $\sim 4$ months); secondary endpoints included hematological effects (hemoglobin level, white cell count, neutrophil count and platelet count) during the treatment course and whole genome gene expression changes at the end of the treatment course (24).

$R N A$ isolation and $c R N A$ synthesis. Approximately $15 \mathrm{ml}$ peripheral whole blood was collected by a phlebotomist using mini-puncture following four courses of chemotherapy treatment with or without concurrent use of rikkunshito. PBMCs were isolated, washed in PBS, transferred and stored in RNAlater ${ }^{\circledR}$ (Ambion; Thermo Fisher Scientific, Inc., Waltham, MA, USA) at $-80^{\circ} \mathrm{C}$ until RNA isolation. A RiboPure-Blood kit (Ambion; Thermo Fisher Scientific, Inc.) was used to isolate high quality total RNA. Samples were run using an RNA 6000 Nano Gel kit on an Agilent 2100 Bioanalyzer (both from Agilent Technologies, Inc., Santa Clara, CA, USA) to determine RNA quality and $2 \mu \mathrm{l}$ RNA was used to determine RNA concentration using a NanoDrop spectrophotometer (Thermo Fisher Scientific, Inc.). Only samples with A260/A280 ratios of 1.9 to 2.1 were used for further studies.
A total of 300 ng RNA was used for in vitro transcription of cRNA using the Illumina ${ }^{\circledR}$ Totalprep ${ }^{\mathrm{TM}}$ RNA Amplication kit (Ambion; Thermo Fisher Scientific, Inc.).

Gene expression profiling. The Illumina HumanRef-8V2 BeadChip (Illumina, Inc., San Diego, CA, USA) was used to generate expression profiles of $>22,000$ transcripts with $750 \mathrm{ng}$ labeled cRNA. All expression profiles are available at NCBI Gene Expression Ominibus (GEO; https://www.ncbi.nlm.nih. gov/geo/) under the series number GSE18309. The probe sets and genes were grouped into functional categories using the Gene Ontology Biological Processes Classification (25).

Microarray data analysis. Statistical analysis of the microarray data was performed using the GeneSpring ${ }^{\mathrm{TM}}$ software version 11 (Sigenics Inc., Chicago, IL, USA). A total of 8,186 probe sets passed the signal filter (which filtered out genes that had low signal close to background level), and were used for further statistical analysis. A non-parametric Wilcoxon signed-rank test for paired comparison of the data prior to and following treatment in the two groups was applied. A change 
Table II. Comparison of the treatment responses and toxicity between the CTH group and the CTH+R group.

\begin{tabular}{|c|c|c|c|c|c|}
\hline Variable & $\begin{array}{c}\text { CTH group, } \\
n=8\end{array}$ & & $\begin{array}{c}\text { CTH+R group, } \\
\qquad n=9\end{array}$ & & P-value \\
\hline Treatment response, $\mathrm{n}(\%)$ & & & & & 0.415 \\
\hline Partial response & $2(25)$ & & $4(44.4)$ & & \\
\hline Stable disease & $3(37.5)$ & & $4(44.4)$ & & \\
\hline Progressive disease & $3(37.5)$ & & $1(11.1)$ & & \\
\hline Change of tumor size (maximum diameter), $\mathrm{cm}$ & $-0.075 \pm 2.12$ & & $0.532 \pm 1.29$ & & 0.501 \\
\hline Events of toxicity & All & $\mathrm{CDC}$ grade $\geq 3$ & All & CDC grade $\geq 3$ & \\
\hline Anorexia & 22 & 2 & 24 & 1 & \\
\hline Nausea & 12 & 1 & 20 & 1 & \\
\hline Vomiting & 8 & 1 & 20 & 2 & \\
\hline Fatigue & 29 & 3 & 44 & 4 & \\
\hline Dyspnea & 6 & 1 & 3 & 1 & \\
\hline Anemia & 6 & 0 & 14 & 2 & \\
\hline Neutropenia & 10 & 4 & 6 & 2 & \\
\hline Thrombocytopenia & 1 & 0 & 4 & 0 & \\
\hline \multicolumn{6}{|l|}{ Blood data } \\
\hline White cell count at baseline, cells $/ \mu 1$ & $5,885 \pm 841$ & & $8,111 \pm 2,659$ & & 0.052 \\
\hline Absolute neutrophil count at baseline & $3,628 \pm 916$ & & $5,326 \pm 2,960$ & & 0.168 \\
\hline Absolute monocyte count at baseline & $50.5 \pm 43.3$ & & $47.6 \pm 19.6$ & & 0.859 \\
\hline Absolute lymphocyte count at baseline & $220 \pm 127.8$ & & $192.8 \pm 92.3$ & & 0.628 \\
\hline Hemoglobin at baseline, $\mathrm{g} / \mathrm{dl}$ & $14.2 \pm 1.2$ & & $12.1 \pm 1.6$ & & $0.014^{\mathrm{a}}$ \\
\hline Platelets at baseline, $1,000 / \mu 1$ & $223.4 \pm 40.3$ & & $311.4 \pm 107.1$ & & 0.600 \\
\hline${ }^{\mathrm{b}}$ Max. Change of white cell count, cells $/ \mu 1$ & $58.6 \pm 1,760$ & & $-2,125.6 \pm 1,750$ & & $0.034^{\mathrm{a}}$ \\
\hline${ }^{\mathrm{b}}$ Max. Change of absolute neutrophil count & $-593 \pm 1,938$ & & $-3,206 \pm 2,242$ & & $0.030^{\mathrm{a}}$ \\
\hline${ }^{\mathrm{b}}$ Max. Change of absolute lymphocyte count & $-104 \pm 553$ & & $-184 \pm 717$ & & 0.491 \\
\hline${ }^{\mathrm{b}}$ Max. Change of absolute monocyte count & $96 \pm 120$ & & $-71 \pm 251$ & & 0.138 \\
\hline${ }^{b}$ Max. Change of hemoglobin, g/dl & $-1.24 \pm 0.84$ & & $-1.04 \pm 1.62$ & & 0.916 \\
\hline${ }^{\mathrm{b}}$ Max. Change of platelets, $1,000 / \mu 1$ & $-18 \pm 23$ & & $-586 \pm 932$ & & 0.368 \\
\hline
\end{tabular}

All data are presented as the mean \pm standard deviation unless otherwise specified. ${ }^{a} \mathrm{P}<0.05$. ${ }^{\text {bV }}$ alue prior to treatment minus mean value of the lowest one following each course of chemotherapy treatment. CTC, National Cancer Institute Common Terminology Criteria; CTH, combination chemotherapy group; CTH+R group, combination chemotherapy plus rikkunshito group; Max., maximum.

in expression of $>1.5$-fold and $\mathrm{P}<0.05$ was used to define the optimal subsets of significantly up- and down-regulated genes.

Statistical analysis. Continuous values are presented as mean \pm standard deviation. Mann-whitney, Wilcoxon ranked sum, Kruskal-Wallis $H$ and $\chi^{2}$ tests were used to assess the differences between different groups, where appropriate. Survival curves were constructed using the Kaplan-Meier method. Cox regression was used to identify independent survival factors. Stepwise multiple linear regression analysis was used to adjust for age, tumor stage, and other confounding factors and obtain adjusted P-values comparing continual variables between the two study groups. All tests were two tailed and $\mathrm{P}<0.05$ was considered to indicate a significant difference. The SPSS statistical software package version 15.0 (SPSS Inc; Chicago, IL, USA) was used for data analysis.

\section{Results}

Clinical effects of combination chemotherapy with or without rikkunshito in patients with advanced stage NSCLC. Between August 2007 and January 2009, 26 patients with newly diagnosed stage IIIb or IV NSCLC were screened. A total of 9 patients were excluded; 6 refused to participate in the study, 2 had other concomitant malignancies and one was receiving concurrent radiotherapy. A total of 17 patients were thus enrolled in the current study. Patients were randomized to the CTH arm $(n=8)$ or $\mathrm{CTH}+\mathrm{R}$ arm $(n=9)$ and all patients completed follow-up. One-year survival follow-up was completed in January 2010. Patients in the CTH arm received a median of 4 (range 3-5) cycles of combination chemotherapy and patients in the $\mathrm{CTH}+\mathrm{R}$ arm received a median of 4 (range 2-6) cycles of combination chemotherapy as well as a daily dose of rikkunshito (cycle numbers of combination chemotherapy, CTH vs. CTH+R arm, $\mathrm{P}=0.705)$. The demographic 

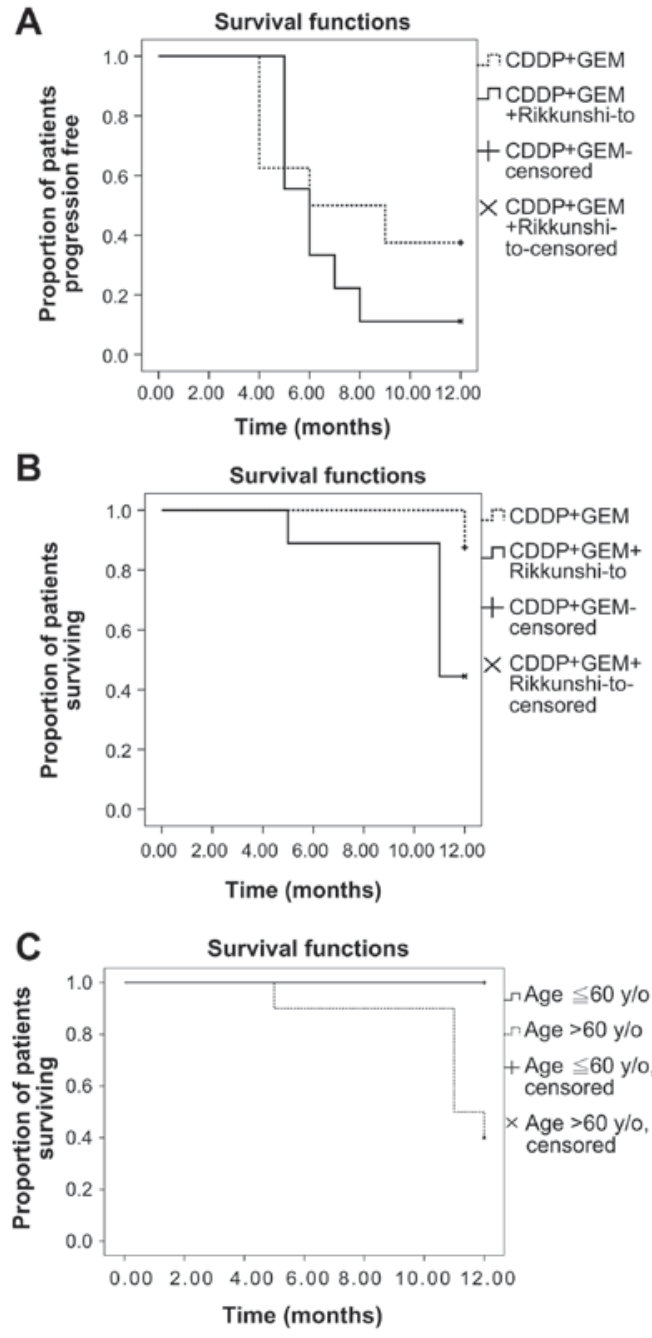

Figure 1. One-year survival analysis for the patients with lung cancer treated with $\mathrm{CTH}$ alone (CDDP+GEM) or CTH + rikkunshito. (A) Kaplan-Meier estimates of 1-year progression free survival ( $\mathrm{P}=0.390$, Log-Rank test) (B) Kaplan-Meier estimates of 1-year overall survival $(\mathrm{P}=0.058$, Log-Rank test). (C) Kaplan-Meier estimates demonstrated that patients $\leq 60$ years old had a better 1-year survival rate than those $>60$ years old $(\mathrm{P}=0.015$, Log-Rank test). CTH, cisplatin (CDDP)-based chemotherapy; CDDP, cisplatin; GEM, gemcitabine.

and clinicopathological characteristics of the 17 patients are presented in Table I. Both groups were matched in age, sex, smoking history, tumor stage, ECOG performance status, histopathology subtype, tumor size, co-morbidity and doses of chemotherapy agents administered. Blood cell counts at baseline were similar, apart from significantly lower hemoglobin levels $(\mathrm{P}=0.014)$ observed in the $\mathrm{CTH}+\mathrm{R}$ group compared with the $\mathrm{CTH}$ group. Following a median of four courses of chemotherapy, the patients in the CTH+R group experienced greater maximum changes in white cell count $(\mathrm{P}=0.034)$ and absolute neutrophil count $(\mathrm{P}=0.030)$, compared with patients in the $\mathrm{CTH}$ alone group, following adjustment for age, tumor stage and other confounding factors by stepwise multiple linear regression analysis (Table II). This means that patients with NSCLC in the CTH+R group exhibited more severe $\mathrm{CTH}$-induced neutropenia compared with patients in the CTH group. There were no significant differences in other outcomes between the two groups in terms of PFS, OS,
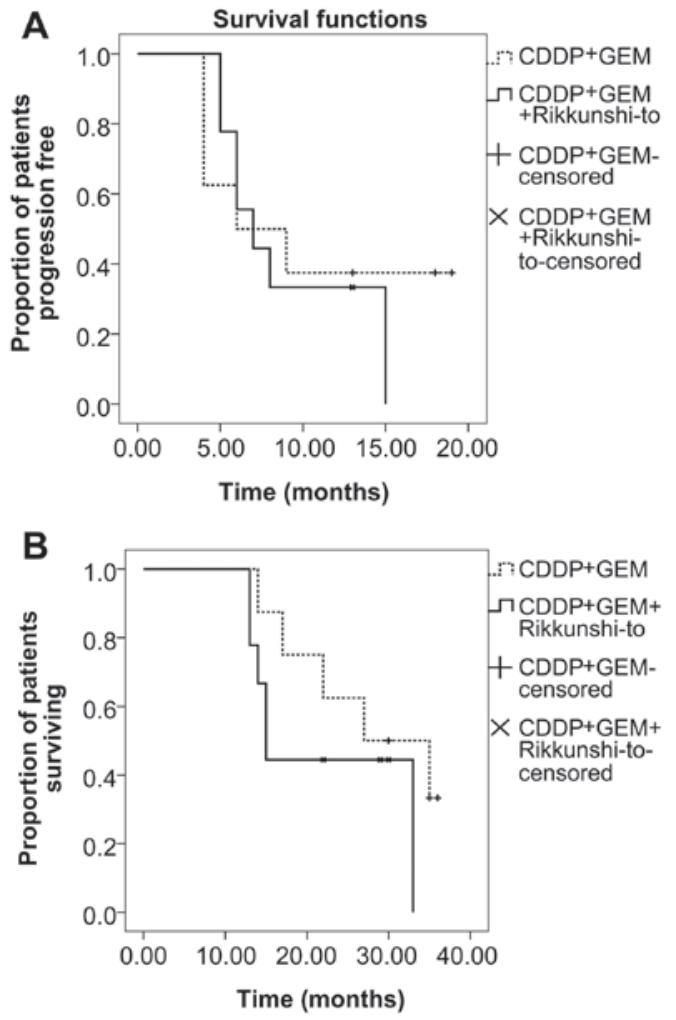

Figure 2. Three-year survival analysis for the patients with lung cancer patients treated with $\mathrm{CTH}$ alone $(\mathrm{CDDP}+\mathrm{GEM})$ or $\mathrm{CTH}+$ rikkunshito. (A) Kaplan-Meier estimates of 3-year progression free survival $(\mathrm{P}=0.591$, Log-Rank test). (B) Kaplan-Meier estimates of 3-year overall survival ( $\mathrm{P}=0.261$, Log-Rank test). CTH, cisplatin (CDDP)-based chemotherapy; CDDP, cisplatin; GEM, gemcitabine.

treatment response, change in tumor size, subjective adverse reactions and maximum changes in hemoglobin level or platelet count from baseline (Table II). Based on Kaplan-Meier estimates (Fig. 1A), median PFS was 6 months in both the $\mathrm{CTH}$ and $\mathrm{CTH}+\mathrm{R}$ groups $(\mathrm{P}=0.390, \log$-rank test). There was 1 case of patient mortality in the CTH group and 5 cases in the $\mathrm{CTH}+\mathrm{R}$ group. Median one-year OS was 12 months in the CTH group and 11 months in the $\mathrm{CTH}+\mathrm{R}$ group $(\mathrm{P}=0.058$, log-rank test; Fig. 1B). The one-year survival rate was $87.5 \%$ for the $\mathrm{CTH}$ arm and $44.4 \%$ for the CTH+R arm. Multivariate Cox regression analysis determined that old age [aged $>60$ years; hazard ratio 1.095, 95\% confidence interval (CI) 1.09-1.189; $\mathrm{P}=0.030]$ was the only independent factor associated with one-year mortality when adjusting for blood laboratory data, tumor stage, ECOG performance status, histology subtype and treatment group. Kaplan-Meier estimates determined that patients aged $\leq 60$ years had a better one-year survival rate than those aged $>60$ years $(\mathrm{P}=0.015$, log-rank test; Fig. 1C). The three-year PFS (median 6 vs. 7 months, $\mathrm{P}=0.591$; Fig. 2A) and $\mathrm{OS}$ (median 27 vs. 15 months, $\mathrm{P}=0.261$; Fig. $2 \mathrm{~B}$ ) were similar in both groups. Clinical benefit, defined as a complete response (CR), partial response (PR), stable disease (SD) or progressive disease (PD), as well as the frequency of subjective toxicity events, was similar between all patients in the two arms (Table II). There were 2 (25\%) PR cases, 3 (37.5\%) SD cases and $3(37.5 \%)$ PD cases in the CTH arm, compared with $4(44.4 \%)$ PR cases, 4 (44.4\%) SD cases and 1 (11.1\%) PD case in the $\mathrm{CTH}+\mathrm{R}$ arm $(\mathrm{P}=0.415)$. 
Table III. Selected microarray gene sets significantly altered before and after chemotherapy in the CTH+R group and regulated in the opposite direction before and after chemotherapy in the CTH group by Gene Ontology analysis.

\begin{tabular}{|c|c|c|c|c|}
\hline \multirow[b]{2}{*}{ Gene symbol } & \multicolumn{2}{|c|}{ Fold change } & \multirow[b]{2}{*}{ Ensembl ID } & \multirow[b]{2}{*}{ Description } \\
\hline & $\begin{array}{c}\text { After/ } \\
\text { before } \mathrm{CTH}+\mathrm{R}\end{array}$ & $\begin{array}{l}\text { After/ } \\
\text { before CTH }\end{array}$ & & \\
\hline \multicolumn{5}{|c|}{ Up-regulated DEGs } \\
\hline \multicolumn{5}{|c|}{$\begin{array}{l}\text { Defense response to other } \\
\text { organism and cell killing }\end{array}$} \\
\hline GNLY & 1.9396 & -2.5559 & ENSG00000115523 & Granulysin \\
\hline LTF & 1.8497 & -1.0959 & ENSG00000012223 & Lactotransferrin \\
\hline CAMP & 1.9233 & 1.0559 & ENSG00000164047 & $\begin{array}{l}\text { Cathelicidin antimicrobial } \\
\text { peptide }\end{array}$ \\
\hline DEFA3 & 3.5452 & 1.1143 & ENSG00000239839 & $\begin{array}{l}\text { Defensin, } \alpha 3 \text {, neutrophil- } \\
\text { specific }\end{array}$ \\
\hline DEFA4 & 3.1757 & -1.1284 & ENSG00000164821 & $\begin{array}{l}\text { Defensin, } \alpha 4 \text {, cortico } \\
\text { statin }\end{array}$ \\
\hline PRF1 & 1.6845 & -1.7414 & ENSG00000180644 & $\begin{array}{l}\text { Perforin } 1 \text { (pore forming } \\
\text { protein) }\end{array}$ \\
\hline DDIT4 & 2.0889 & -1.0391 & ENSG00000168209 & $\begin{array}{l}\text { DNA-damage-inducible } \\
\text { transcript } 4\end{array}$ \\
\hline RNASE3 & 2.2979 & -1.0209 & ENSG00000169397 & $\begin{array}{l}\text { Ribonuclease, RNase A } \\
\text { family, } 3\end{array}$ \\
\hline CTSG & 3.1563 & 1.2024 & ENSG00000100448 & Cathepsin G \\
\hline MPO & 2.0649 & 1.1206 & ENSG00000005381 & Myeloperoxidase \\
\hline AZU1 & 2.1764 & -1.0712 & ENSG00000172232 & Azurocidin 1 \\
\hline PGLYRP1 & 1.6233 & -1.0181 & ENSG00000008438 & $\begin{array}{l}\text { Peptidoglycan recognition } \\
\text { protein } 1\end{array}$ \\
\hline BPI & 2.1614 & -1.0686 & ENSG00000101425 & $\begin{array}{l}\text { Bactericidal/permeability- } \\
\text { increasing protein }\end{array}$ \\
\hline \multicolumn{5}{|c|}{ Serine-type endopeptidase activity } \\
\hline MMP8 & 1.5489 & 1.0208 & ENSG00000118113 & $\begin{array}{l}\text { Matrix metallopeptidase } 8 \\
\text { (neutrophil collagenase) }\end{array}$ \\
\hline GZMB & 1.5678 & -2.2774 & ENSG00000100453 & $\begin{array}{l}\text { Granzyme B (granzyme } 2 \text {, } \\
\text { cytotoxic T-lymphocyte-associated } \\
\text { serine esterase } 1 \text { ) }\end{array}$ \\
\hline PRTN3 & 1.6904 & -1.0385 & ENSG00000196415 & Proteinase 3 \\
\hline ELANE & 2.8886 & 1.2484 & ENSG00000197561 & Elastase, neutrophil expressed \\
\hline LTF & 1.84967 & -1.09597 & ENSG00000012223 & Lactotransferrin \\
\hline CTSG & 3.15631 & 1.2024 & ENSG00000100448 & Cathepsin G \\
\hline AZU1 & 2.17641 & -1.07115 & ENSG00000172232 & Azurocidin 1 \\
\hline \multicolumn{5}{|c|}{ Down-regulated DEGs } \\
\hline \multicolumn{5}{|c|}{ Blood coagulation and } \\
\hline \multicolumn{5}{|c|}{ Leukocyte migration } \\
\hline MPL & -1.7269 & 1.0134 & ENSG00000117400 & $\begin{array}{l}\text { myeloproliferative leukemia } \\
\text { virus oncogene }\end{array}$ \\
\hline PROS1 & -1.6932 & -1.0417 & ENSG00000184500 & protein $S$ (alpha) \\
\hline GP IX & -2.1117 & -1.5528 & ENSG00000169704 & glycoprotein IX (platelet) \\
\hline PF4V1 & -1.8459 & -1.3522 & ENSG00000109272 & platelet factor 4 variant 1 \\
\hline PPBP & -1.5451 & -1.4881 & ENSG00000163736 & $\begin{array}{l}\text { pro-platelet basic protein } \\
\text { (chemokine (C-X-C motif) } \\
\text { ligand 7) }\end{array}$ \\
\hline F13A1 & -1.9439 & 1.0911 & ENSG00000124491 & $\begin{array}{l}\text { coagulation factor XIII, A1 } \\
\text { polypeptide }\end{array}$ \\
\hline
\end{tabular}


Table III. Continued.

\begin{tabular}{|c|c|c|c|c|}
\hline \multirow[b]{2}{*}{ Gene symbol } & \multicolumn{2}{|c|}{ Fold change } & \multirow[b]{2}{*}{ Ensembl ID } & \multirow[b]{2}{*}{ Description } \\
\hline & $\begin{array}{c}\text { After/ } \\
\text { before CTH+R }\end{array}$ & $\begin{array}{c}\text { After/ } \\
\text { before CTH }\end{array}$ & & \\
\hline \multicolumn{5}{|c|}{ Down-regulated DEGs } \\
\hline \multicolumn{5}{|c|}{ Blood coagulation and } \\
\hline \multicolumn{5}{|c|}{ Leukocyte migration } \\
\hline AMICA1 & -1.5582 & 1.2624 & ENSG00000160593 & $\begin{array}{l}\text { Adhesion molecule, interacts with } \\
\text { CXADR antigen } 1\end{array}$ \\
\hline JAM3 & -1.5204 & -1.0827 & ENSG00000166086 & Junctional adhesion molecule 3 \\
\hline ITGA2B & -1.8320 & -1.5962 & ENSG00000005961 & $\begin{array}{l}\text { Integrin, } \alpha 2 b \text { (platelet } \\
\text { glycoprotein IIb of IIb/IIIa } \\
\text { complex, antigen CD41) }\end{array}$ \\
\hline GP1BB & -1.9588 & -1.4438 & ENSG00000203618 & $\begin{array}{l}\text { Glycoprotein } \mathrm{Ib} \text { (platelet), } \beta \\
\text { polypeptide }\end{array}$ \\
\hline \multicolumn{5}{|c|}{$\begin{array}{l}\text { Integral component of } \\
\text { plasma membrane }\end{array}$} \\
\hline ABCA1 & -1.5772 & 1.2133 & ENSG00000165029 & $\begin{array}{l}\text { ATP-binding cassette, sub-family } \\
\text { A (ABC1), member } 1\end{array}$ \\
\hline TSPAN9 & -1.5341 & -1.3441 & ENSG00000011105 & Tetraspanin 9 \\
\hline CLEC1B & -1.7081 & -1.0492 & ENSG00000165682 & $\begin{array}{l}\text { C-type lectin domain family } \\
1, \text { member B }\end{array}$ \\
\hline AQP9 & -1.5495 & 1.0015 & ENSG00000103569 & Aquaporin 9 \\
\hline MMD & -1.9804 & -1.1803 & ENSG00000108960 & $\begin{array}{l}\text { Monocyte to macrophage } \\
\text { differentiation-associated }\end{array}$ \\
\hline CYBB & -1.5066 & 1.2194 & ENSG00000165168 & $\begin{array}{l}\text { Cytochrome b-245, beta } \\
\text { polypeptide }\end{array}$ \\
\hline DAB2 & -1.7146 & -1.0331 & ENSG00000153071 & $\begin{array}{l}\text { Dab, mitogen-responsive } \\
\text { phosphoprotein, homolog } 2 \text { (Drosophila) }\end{array}$ \\
\hline
\end{tabular}

$\mathrm{CTH}$, combination chemotherapy group; $\mathrm{CTH}+\mathrm{R}$ group, combination chemotherapy plus rikkunshito group; DEG, differentially expressed genes.

Distinct gene expression signature changes associated with Rikkunshito and chemotherapy relative to chemotherapy alone. Gene expression data prior to and following treatment was compared between the $\mathrm{CTH}+\mathrm{R}$ and $\mathrm{CTH}$ groups, respectively and fold change was obtained by dividing the log ratios of gene expression intensity following treatment by the data collected prior to treatment. A total of 159 differentially expressed genes (DEG) were identified to be significantly up or down regulated in the $\mathrm{CTH}+\mathrm{R}$ group following treatment, which were regulated in the opposite direction or remained unchanged in the CTH group. Among these, 111 genes were up-regulated and 48 genes were down-regulated following rikkunshito treatment. Gene ontology analysis demonstrated that gene sets mapping to defensive responses to other organisms, immune cell killing and serine-type endopeptidase activity pathways were up-regulated following rikkunshito treatment, whereas gene sets mapping to blood coagulation, thrombosis, leukocyte migration and integral component of plasma membrane pathways were down-regulated (Table III). Genes up-regulated following with rikkunshito treatment (Table IV) were associated with neutrophil apoptosis [elastase (ELANE), proteinase 3 (PRTN3), cathepsin G $(C T S G)$, cluster of differentiation $(C D) 24]$, cell-killing or bactericidal ability of neutrophil [defensin $\alpha$ 1-3 (DEF Al, $A 2, A 3)$, bactericidal/permeability-increasing protein $(B P I)]$, natural killer (NK) cell activation [killer cell immunoglobulin-like receptor (KIR2DL1-3), killer cell lecti n-like receptor $(K L R), K I R 2 D S 5, N K$ group 7 (NKG7)] and B cell proliferation [CD19, membrane-spanning 4-domains (MS4A3), CD79A, CD79B and tumor necrosis factor receptor superfamily (TNFRSF13B/17). Genes that were down-regulated following rikkunshito treatment (Table IV) were associated with neutrophil migration [prostaglandin endoperoxide synthase 1 (PTGS1; cyclooxygenase 1,COX1), monophosphoryl lipid A $(M P L)$, junctional adhesion molecule 3 (JAM3), adhesion molecule interacts with $C X A D R$ antigen 1 (AMICA1;JAML)], coagulation [coagulation factor XIII (F13Al)], thrombosis [glycoprotein IX $(G P I X)$, platelet factor 4 variant 1 (PF4VI), pro-platelet basic protein $(P P B P)$, integrin $\alpha 2 \mathrm{~b}(I T G A 2 B$; 
Table IV. Selected microarray of DEGs significantly altered before and after chemotherapy in the CTH+R group and regulated in the opposite direction before to and after chemotherapy in the CTH group.

\begin{tabular}{|c|c|c|c|c|}
\hline \multirow[b]{2}{*}{ Gene symbol } & \multicolumn{2}{|c|}{ Fold change } & \multirow[b]{2}{*}{ Ensembl ID } & \multirow[b]{2}{*}{ Description } \\
\hline & $\begin{array}{l}\text { After/ } \\
\text { before } \mathrm{CTH}+\mathrm{R}\end{array}$ & $\begin{array}{c}\text { After/ } \\
\text { before CTH }\end{array}$ & & \\
\hline \multicolumn{5}{|l|}{ Up-regulated DEGs } \\
\hline \multicolumn{5}{|c|}{ Surface molecules of B cells } \\
\hline CD19 & 1.9084 & -1.7289 & ENSG00000177455 & CD19 molecule \\
\hline MS4A1 (CD20) & 1.5698 & -1.0989 & ENSG00000156738 & $\begin{array}{l}\text { membrane-spanning 4-domains, } \\
\text { subfamily A, member } 1\end{array}$ \\
\hline $\mathrm{CD} 24$ & 1.5597 & 1.0210 & ENSG00000272398 & CD24 molecule \\
\hline CD79A & 2.0026 & -1.5466 & ENSG00000105369 & $\begin{array}{l}\text { CD79a molecule, immunoglobulin- } \\
\text { associated } \alpha\end{array}$ \\
\hline CD79B & 1.6759 & -1.3398 & ENSG00000007312 & $\begin{array}{l}\text { CD79b molecule, immunoglobulin- } \\
\text { associated } \beta\end{array}$ \\
\hline TNFRSF13B (CD267) & 1.5603 & -1.3878 & ENSG00000240505 & $\begin{array}{l}\text { tumor necrosis factor receptor } \\
\text { superfamily, member } 13 \mathrm{~B}\end{array}$ \\
\hline TNFRSF17 (CD268) & 1.5128 & -1.0736 & ENSG00000048462 & $\begin{array}{l}\text { tumor necrosis factor receptor } \\
\text { superfamily, member } 17\end{array}$ \\
\hline PRL & 1.52987 & -1.16365 & ENSG00000172179 & Prolactin \\
\hline \multicolumn{5}{|c|}{ Surface molecules of NK cells } \\
\hline KIR2DL1 (CD158A) & 1.5137 & -2.1425 & ENSG00000125498 & $\begin{array}{l}\text { Killer cell immunoglobulin-like } \\
\text { receptor, two domains, long } \\
\text { cytoplasmic tail, } 1\end{array}$ \\
\hline KIR2DL2 (CD158B1) & 1.5478 & -2.3593 & ENSG00000277725 & $\begin{array}{l}\text { Killer cell immunoglobulin-like } \\
\text { receptor, two domains, long } \\
\text { cytoplasmic tail, } 2\end{array}$ \\
\hline KIR2DL3 (CD158B2) & 1.5771 & -1.8231 & ENSG00000243772 & $\begin{array}{l}\text { Killer cell immunoglobulin-like } \\
\text { receptor, two domains, long } \\
\text { cytoplasmic tail, } 3\end{array}$ \\
\hline KIR2DL4 (CD158D) & 1.6675 & -1.7716 & ENSG00000189013 & $\begin{array}{l}\text { Killer cell immunoglobulin-like } \\
\text { receptor, two domains, long } \\
\text { cytoplasmic tail, } 4\end{array}$ \\
\hline KLRK1 (CD314) & 1.5105 & -1.8145 & ENSG00000213809 & $\begin{array}{l}\text { Killer cell lectin-like receptor subfamily } \\
\mathrm{K} \text {, member } 1\end{array}$ \\
\hline KLRD1 (CD94) & 1.5437 & -1.7995 & ENSG00000134539 & $\begin{array}{l}\text { Killer cell lectin-like receptor subfamily } \\
\text { D, member } 1\end{array}$ \\
\hline KIR2DS5 (CD158G) & 1.5378 & -2.2766 & ENSG00000277650 & $\begin{array}{l}\text { Killer cell immunoglobulin-like } \\
\text { receptor, two domains, short } \\
\text { cytoplasmic tail, } 5\end{array}$ \\
\hline \multicolumn{5}{|l|}{ Down-regulated DEGs } \\
\hline \multicolumn{5}{|c|}{$\begin{array}{l}\text { Positive regulation of neutrophil } \\
\text { counts or activation }\end{array}$} \\
\hline PTGS1 & -1.8308 & -1.0724 & ENSG00000095303 & Prostaglandin-endoperoxide synthase 1 \\
\hline PGRMC1 & -1.7732 & -1.0262 & ENSG00000101856 & $\begin{array}{l}\text { Progesterone receptor membrane } \\
\text { component } 1\end{array}$ \\
\hline MPL & -1.72699 & -1.30672 & ENSG00000117400 & $\begin{array}{l}\text { Proto-oncogene, thrombopoietin } \\
\text { receptor }\end{array}$ \\
\hline AMICA1 & -1.55819 & -1.07045 & ENSG00000160593 & $\begin{array}{l}\text { Adhesion molecule, interacts with } \\
\text { CXADR antigen } 1\end{array}$ \\
\hline CYBB & -1.50661 & -1.10927 & & \\
\hline PPBP & -1.54508 & -1.48807 & & \\
\hline
\end{tabular}


Table IV. Continued.

\begin{tabular}{lllll}
\hline & \multicolumn{2}{c}{ Fold change } & & \\
\cline { 2 - 3 } Gene symbol & $\begin{array}{c}\text { After/ } \\
\text { before CTH+R }\end{array}$ & $\begin{array}{c}\text { After/ } \\
\text { before CTH }\end{array}$ & Ensembl ID & Description \\
\hline $\begin{array}{l}\text { Positive regulation by } \\
\text { activated neutrophils } \\
\text { IFIT1 }\end{array}$ & & & & \\
PF4V1 & -1.6140 & 1.2178 & ENSG00000185745 & $\begin{array}{l}\text { Interferon-induced protein with } \\
\text { tetratricopeptide repeats 1 }\end{array}$ \\
ITGA2B & -1.3522 & -1.8459 & ENSG00000109272 & Platelet factor 4 variant 1 \\
\hline
\end{tabular}

$\mathrm{CTH}$, combination chemotherapy group; $\mathrm{CTH}+\mathrm{R}$ group, combination chemotherapy plus rikkunshito group; DEG, differentially expressed genes; $\mathrm{CD}$, cluster of differentiation.

GP IIb of IIb/IIIa complex), glycoprotein Ib (GPIBB), MPL)] and type I interferon (IFN) signaling [interferon-induced protein with tetratricopeptide repeats 1 (IFIT1), IFIT2)]. Gene interaction analysis demonstrated a consistent result (Fig. 3), indicating that rikkunshito may inhibit neutrophil migration by down-regulating MPL, PTGS1, AMICA1, JAM3 and IFIT, while enhancing the cell-killing ability of neutrophils by up-regulating ELANE, PREN3, BPI and DEF.

\section{Discussion}

Rikkunshito is a Chinese and Japanese herbal medicine that is widely used to treat upper gastrointestinal symptoms, including functional dyspepsia, gastroesophageal reflux disease, dyspeptic symptoms in patients following post gastrointestinal surgery, and chemotherapy-induced dyspepsia in patients with cancer $(18,19)$. The anti-emetic effect of rikkunshito occurs via the stimulation of endogenous ghrelin secretion by blocking the serotonin (5-HT) $2 b / 2 c / 3$ receptor pathway and inhibiting the expression of substance $\mathrm{P} /$ calcitonin gene-related peptide/phosphorylated extracellular signal-regulated kinase 1/2 (26). In the current randomized controlled trial, no significant differences in the frequency of anorexia, nausea or vomiting were observed between the $\mathrm{CTH}+\mathrm{R}$ and CTH groups. Notably, it was determined that patients with NSCLC in the CTH+R group exhibited more severe CTH-induced neutropenia than patients in the $\mathrm{CTH}$ group, however both groups had similar PFS and OS. Previous studies have demonstrated that $\mathrm{CTH}$-induced neutropenia is an independent factor of better survival in patients with lung cancer (8-11), therefore it has been suggested that rikkunshito may exert potential effects on disease control when used in combination with the CDDP+GEM CTH regimen. Abnormal expression of transport protein, enhancement of intracellular detoxification, an increase in DNA repair capacity and the blocking of apoptosis are the primary mechanisms underlying cancer resistance to CDDP (27). Furthermore, ginseng radix, one of the primary ingredients of rikkunshito, has been found to exert antitumor, antioxidant, and immunomodulation activities through its pro-apoptotic and anti-cell cycle effects (28-30). The netropenic effect may only occur when rikkunshito is used in combination with anti-cancer drugs, since such an effect is not universally recognized under its general usage.

Microarray gene expression comparison between pre- and post-treatment data for the $\mathrm{CTH}+\mathrm{R}$ and $\mathrm{CTH}$ groups identified a number of signaling pathways and molecules that were significantly altered following the addition of rikkunshito. Enhanced PTGS1 expression is responsible for persistent neutrophil presence as it impairs its apoptosis (31). It has been demonstrated that JAM3 regulates the polarized transendothelial migration of neutrophils (32), whereas the exogenous expression of AMICA1 (JAML) in leukocytes resulted in enhanced cell adhesion to endothelial cells (33). In the present study, PTGS1, JAM3 and AMICAl were all down-regulated following rikkunshito treatment, indicating the underlying mechanisms by which more severe neutropenia was able to develop in the $\mathrm{CTH}+\mathrm{R}$ group compared with the $\mathrm{CTH}$ group. In accordance with the results of the current study, it has been demonstrated that rikkunshito is able to inhibit the infiltration of neutrophils and macrophages by inhibiting the 5-HT3 receptor and ghrelin release in an animal model (34). Moreover, rikkunshito can ameliorate bleomycin-induced acute lung injury by inhibiting neutrophil alveolar infiltration, pulmonary vascular permeability, the release of pro-inflammatory cytokines, nuclear factor- $\mathrm{kB}$ pathway activation and the apoptosis of alveolar epithelial cells in a ghrelin-independent manner (35). The three serine proteases ELANE, PRTN3 and CTSG are major components of the neutrophil primary granules (36-38). Previous studies have demonstrated that neutrophil ELANE provides a negative feedback to granulopoiesis by direct antagonism of granulocyte colony-stimulating factor, whereas PRTN3-mediated caspase-3 activation and the $C T S G$-dependent pathway contribute to the spontaneous death of neutrophils (36-38). Furthermore, CD24 ligation induces neutrophil death by depolarizing the mitochondrial membrane in a manner dependent on caspase-3 and caspase-9 and reactive oxygen species (39). In the present study, the three neutrophil granules and CD24 genes were all up-regulated following rikkunshito treatment, indicating that it may enhance neutrophil apoptosis. Four human $\alpha$-defensins from the granules of neutrophils (DEF A1-A4) can attract other immune cells, inducing the release of pro-inflammatory cytokines (40). BPI, stored in the primary azurophilic granula of 


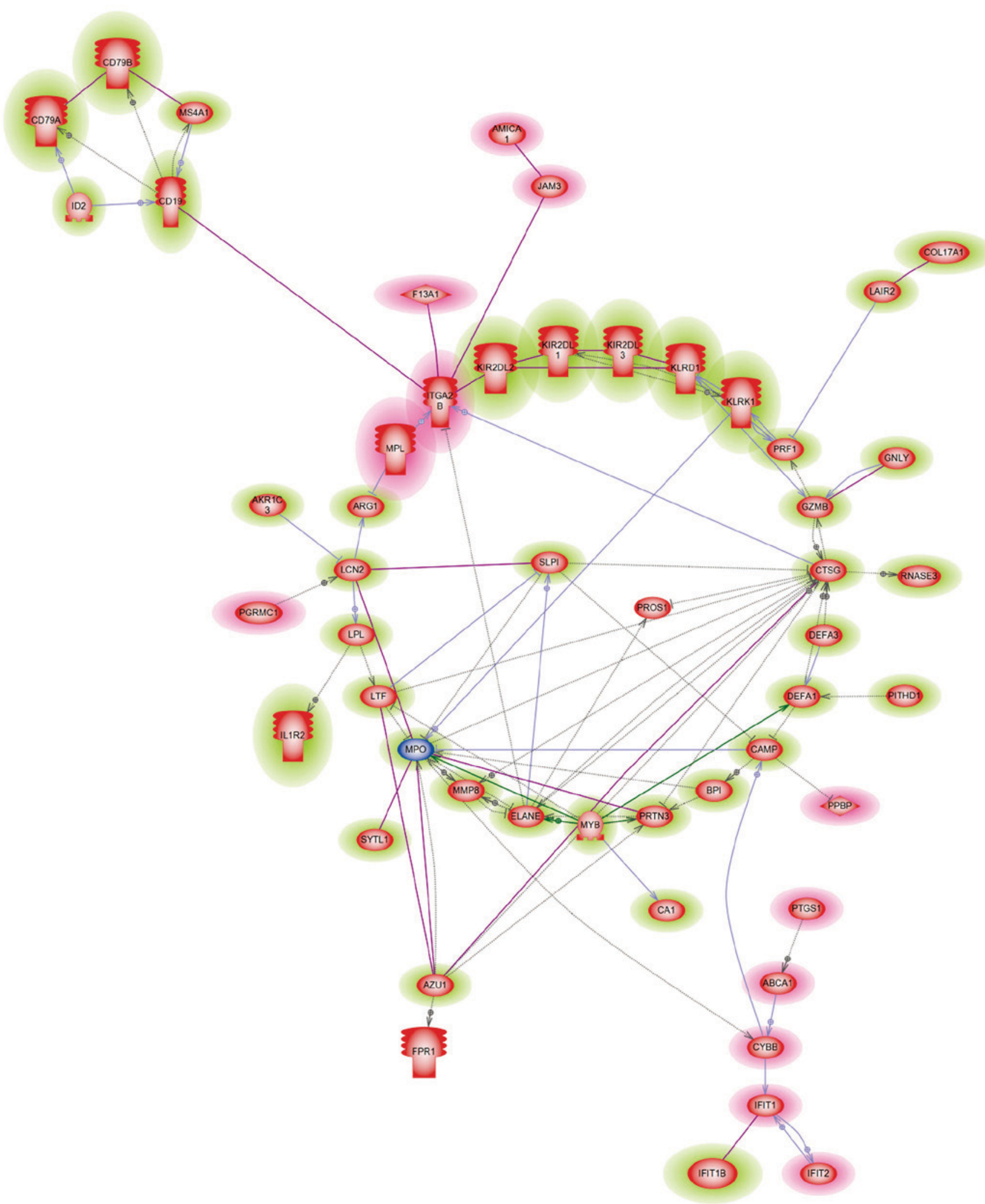

Figure 3. Rikkunshito-regulated signaling pathways. Microarray-identified signaling pathways enriched following the addition of rikkunshito in the chemotherapy regimen for the advanced non-small cell lung cancer patients. The majority of these genes targeted insulin, cyclin-dependent kinase 1, Grb-2-related adaptor protein 2 and interleukin-2.

neutrophil granulocytes, is able to efficiently kill Gram-negative bacteria (41). In the present study $D E F A 1, A 2, A 3$, and $B P I$ were all up-regulated following rikkunshito treatment, indicating a positive effect of rikkunshito on the individual cell-killing function of neutrophils but a negative effect on the recruitment and survival of neutrophils.

The principal inhibitory receptors expressed on $\mathrm{NK}$ cells are KIR (KIR2DL1-3, KIR3DL1), while activating 
receptors include Fc $\gamma$ RIIIA, activating forms of KIR (KIR2DS, KIR3DS), KIR2B4 and NKG2D (42). The mounting of effective anti-tumor immune responses by cytotoxic NK cells via mediation of cancer stem cell lysis is important to facilitate tumor clearance (43). In the present study, a number of inhibitory receptors (KIR2DL1-3,KLR) and activating receptors (KIR2DS5, NKG7) were all up-regulated following rikkunshito treatment, indicating that rikkunshito may exert its potential anti-neoplasm effect by modulating the function of NK cells. CD19 and MS4A3 both serve important roles in B cell receptor (BCR) activation and signaling $(44,45)$, while the extracellular antigen recognizing domain is complexed with CD79A and CD79B that form the cytoplasmic tail of the BCR (46). TNFRSF13B affects T-cell-independent antibody responses (47) and PRL may promote the increased proliferation of lymphocytes (48). In the present study, CD19, MS4A3, CD79A, CD79B, TNFRSF13B, TNFRSF17 and PRL were all up-regulated following rikkunshito treatment, indicating that it may enhance the activation and proliferation of B cells.

F13A1 and MPL serve important roles in coagulation and thrombosis, respectively $(49,50)$, whereas IFITs are involved in drug resistance and metastasis in breast cancer (51). In response to vascular damage, engagement of the platelet receptors GP Ib-IX-V, GPVI and/or Fc $\gamma$ RIIa leads to platelet adhesion and activation (52). A complex coagulopathy characterized by activation of clotting mechanisms develops in parallel with malignancy (53). In the present study, F13A1, MPL, GP Ib, GPIX, GP IIb, IFIT1 and IFIT2 were all down-regulated following rikkunshito treatment, indicating that rikkunshito may exert an anti-neoplasm effect, resulting in the down-regulation of these coagulation/thrombosis pathways.

It has been demonstrated that compromised immune surveillance and inflammatory microenvironments affect aspects of malignancy including proliferation, survival, angiogenesis and tumor metastasis. Neutrophils are recruited to tumor sites through transendothelial migration. This creates an inflammatory environment, which increases the risk of cancer development. By contrast, T cells and NK cells are able to recognize and destroy cancer cells (54). Antibodies that inhibit the checkpoint molecules of $\mathrm{T}$ cells, including cytotoxic T-lymphocyte-associated antigen 4 and programmed death legend 1 , improve the survival and response to treatment in patients with NSCLC (55). Based on the rikkunshito-related genetic signatures, rikkunshito may have multiple pharmaceutical action sites to exert its anti-cancer effects by enhancing neutrophil apoptosis, inhibiting neutrophil migration, promoting NK cell activation, inducing B cell proliferation and ameliorating thrombosis/coagulation pathways. However, further studies are required to determine the exact pharmacological sites of rikkunshito with regard to its antitumor effects.

The limitations and biases of the current study should be addressed. First, only 17 patients with NSCLC were included in the current study and follow-up was completed over short-course study period. The sample size seems to be too small to accurately identify whether there were any significant differences in the major outcomes between the $\mathrm{CTH}$ and $\mathrm{CTH}+\mathrm{R}$ groups. However, despite the small sample size, a greater neutropenic effect following the addition of rikkunshito treatment was observed in the current study. The lack of anti-emetic effect following rikkunshito treatment in the current randomized controlled trial may be due to strong anti-emetic agents, including the 5-HT3 receptor antagonists, metoclopramide and dexamethasone administered, to all 17 participants. Secondly, hemoglobin levels were lower and age was slightly greater in the $\mathrm{CTH}+\mathrm{R}$ group at baseline. However, the maximum changes following treatment revealed that rikkunshito primarily affected white blood cell and neutrophil count, rather than hemoglobin levels. Moreover, Cox regression model analysis was performed to adjust the effect of the confounding factors on clinical outcomes. Finally, the changes in gene expression identified by the microarray analysis were not validated by quantitative real-time reverse transcript polymerase chain reaction due to the inadequate number of RNA samples. Despite these limitations, to the best of our knowledge, the present study is the first to assess the potential molecular mechanisms and genes associated with the clinical effects of rikkunshito on a genome-wide scale.

In conclusion, the current study identified the potential effect of rikkunshito treatment on reducing blood total leukocyte and absolute neutrophil counts in patients with advanced NSCLC receiving first line CTH with CDDP and GEM. Rikkunshito did not exert a prominent anti-emetic effect or affect other outcomes, including response rates and survival. Microarray gene expression analyses identified a number of signaling pathways and gene sets that may be involved in the underlying mechanisms by which rikkunshito functions to enhance the cell-killing ability of neutrophils, activate NK cells and B cell proliferation and inhibit coagulation/thrombosis. Gene Ontology analyses suggest that PTGSI, MPL, AMICA1 and JAM 3 may be involved in the development of more severe CT-induced neutropenia by inhibiting neutrophil apoptosis whereas ELANE, PRTN3, $C T S G$ and $C D 24$ may act by enhancing the transendothelial migration and adhesion of neutrophils following the addition of rikkunshito.

\section{Acknowledgements}

The authors acknowledge the technical support provided by the Genomic and Proteomic Core Laboratory, and Internal Medicine Core Facility of the Kaohsiung Chang Gung Memorial Hospital. The present study was supported by a grant (CCMP96-RD-202/PMRPG860121-860122 to M.C. Lin) from the Committee on Chinese Medicine and Pharmacy of the Department of Health, Executive Yuan, Taiwan and also partly supported by grants from the Chang Gung Memorial Hospital (CMRPG891301 to K.D. Chen, and CMRPG8C0221-222 to Y.C. Chen). The funders had no role in study design, data collection and analysis, decision to publish, or preparation of the manuscript.

\section{References}

1. Dubey AK, Gupta U and Jain S: Epidemiology of lung cancer and approaches for its prediction: A systematic review and analysis. Chin J Cancer 35: 71, 2016.

2. Didkowska J, Wojciechowska U, Mańczuk M and Łobaszewski J: Lung cancer epidemiology: Contemporary and future challenges worldwide. Ann Transl Med 4: 150, 2016.

3. Hong QY, Wu GM, Qian GS, Hu CP, Zhou JY, Chen LA, Li WM, Li SY, Wang K, Wang Q, et al: Prevention and management of lung cancer in China. Cancer 121 (Suppl 17): S3080-S3088, 2015. 
4. Blanco R, Maestu I, de la Torre MG, Cassinello A and Nuñez I: A review of the management of elderly patients with non-small-cell lung cancer. Ann Oncol 26: 451-463, 2015.

5. Pilkington G, Boland A, Brown T, Oyee J, Bagust A and Dickson R: A systematic review of the clinical effectiveness of first-line chemotherapy for adult patients with locally advanced or metastatic non-small cell lung cancer. Thorax 70: 359-367, 2015.

6. Spira A and Ettinger DS: Multidisciplinary management of lung cancer. N Engl J Med 350: 379-392, 2004.

7. Sun L, Ma JT, Zhang SL, Zou HW and Han CB: Efficacy and safety of chemotherapy or tyrosine kinase inhibitors combined with bevacizumab versus chemotherapy or tyrosine kinase inhibitors alone in the treatment of non-small cell lung cancer: A systematic review and meta-analysis. Med Oncol 32: 473, 2015

8. Maione P, Rossi A, Di Maio M and Gridelli C: Tumor-related leucocytosis and chemotherapy-induced neutropenia: Linked or independent prognostic factors for advanced non-small cell lung cancer? Lung Cancer 66: 8-14, 2009.

9. Di Maio M, Gridelli C, Gallo C, Shepherd F, Piantedosi FV, Cigolari S, Manzione L, Illiano A, Barbera S, Robbiati SF, et al: Chemotherapy-induced neutropenia and treatment efficacy in advanced non-small-cell lung cancer: A pooled analysis of three randomised trials. Lancet Oncol 6: 669-677, 2005

10. Pallis AG, Agelaki S, Kakolyris S, Kotsakis A, Kalykaki A, Vardakis N, Papakotoulas P, Agelidou A, Geroyianni A, Agelidou M, et al: Chemotherapy-induced neutropenia as a prognostic factor in patients with advanced non-small cell lung cancer treated with front-line docetaxel-gemcitabine chemotherapy. Lung Cancer 62: 356-363, 2008.

11. Kishida Y, Kawahara M, Teramukai S, Kubota K, Komuta K, Minato K, Mio T, Fujita Y, Yonei T, Nakano K, et al: Chemotherapy-induced neutropenia as a prognostic factor in advanced non-small-cell lung cancer: Results from Japan multinational trial organization LC00-03. Br J Cancer 101: 1537-1542, 2009.

12. Han Y, Yu Z, Wen S, Zhang B, Cao X and Wang X: Prognostic value of chemotherapy-induced neutropenia in early-stage breast cancer. Breast Cancer Res Treat 131: 483-490, 2012

13. Uezono Y, Miyano K, Sudo Y, Suzuki M, Shiraishi S and Terawaki K: A review of traditional Japanese medicines and their potential mechanism of action. Curr Pharm Des 18: 4839-4853, 2012.

14. Ohno T, Yanai M, Ando H, Toyomasu Y, Ogawa A, Morita H, Ogata K, Mochiki E, Asao T and Kuwano H: Rikkunshito, a traditional Japanese medicine, suppresses cisplatin-induced anorexia in humans. Clin Exp Gastroenterol 4: 291-296, 2011.

15. Tominaga K, Kido T, Ochi M, Sadakane C, Mase A, Okazaki H, Yamagami H, Tanigawa T, Watanabe K, Watanabe T, et al: The traditional Japanese medicine rikkunshito promotes gastric emptying via the antagonistic action of the 5-HT(3) receptor pathway in rats. Evid Based Complement Alternat Med 2011: 248481, 2011.

16. Yakabi K, Kurosawa S, Tamai M, Yuzurihara M, Nahata M, Ohno S, Ro S, Kato S, Aoyama T, Sakurada T, et al: Rikkunshito and 5-HT2C receptor antagonist improve cisplatin-induced anorexia via hypothalamic ghrelin interaction. Regul Pept 161: 97-105, 2010

17. Takeda H, Sadakane C, Hattori T, Katsurada T, Ohkawara T, Nagai K and Asaka M: Rikkunshito, an herbal medicine, suppresses cisplatin-induced anorexia in rats via 5-HT2 receptor antagonism. Gastroenterology 134: 2004-2013, 2008.

18. Mogami S and Hattori T: Beneficial effects of rikkunshito, a Japanese kampo medicine, on gastrointestinal dysfunction and anorexia in combination with Western drug: A systematic review. Evid Based Complement Alternat Med 2014: 519035, 2014

19. Fujitsuka N and Uezono Y: Rikkunshito, a ghrelin potentiator, ameliorates anorexia-cachexia syndrome. Front Pharmacol 5 : 271,2014

20. Liu ZL, Zhu WR, Zhou WC, Ying HF, Zheng L, Guo YB, Chen JX and Shen XH: Traditional Chinese medicinal herbs combined with epidermal growth factor receptor tyrosine kinase inhibitor for advanced non-small cell lung cancer: A systematic review and meta-analysis. J Integr Med 12: 346-358, 2014.

21. Mountain CF: Revisions in the International system for staging lung cancer. Chest 111: 1710-1717, 1997.

22. Buccheri G, Ferrigno D and Tamburini M: Karnofsky and ECOG performance status scoring in lung cancer: A prospective, longitudinal study of 536 patients from a single institution. Eur J Cancer 32A: 1135-1141, 1996.
23. Nishino M, Jackman DM, Hatabu H, Yeap BY, Cioffredi LA, Yap JT, Jänne PA, Johnson BE and Van den Abbeele AD: New response evaluation criteria in solid tumors (RECIST) guidelines for advanced non-small cell lung cancer: Comparison with original RECIST and impact on assessment of tumor response to targeted therapy. AJR Am J Roentgenol 195: W221-W228, 2010.

24. Trotti A, Colevas AD, Setser A, Rusch V, Jaques D, Budach V, Langer C, Murphy B, Cumberlin R, Coleman CN and Rubin P: CTCAE v3.0: Development of a comprehensive grading system for the adverse effects of cancer treatment. Semin Radiat Oncol 13: 176-181, 2003.

25. Harris MA, Clark J, Ireland A, Lomax J, Ashburner M, Foulger R, Eilbeck K, Lewis S, Marshall B, Mungall C, et al: The gene ontology (GO) database and informatics resource. Nucleic Acids Res 32: D258-D261, 2004.

26. Kondo T, Oshima T, Koseki J, Hattori T, Kase Y, Tomita T, Fukui H, Watari J and Miwa H: Effect of rikkunshito on the expression of substance $\mathrm{P}$ and CGRP in dorsal root ganglion neurons and voluntary movement in rats with experimental reflux esophagitis. Neurogastroenterol Motil 26: 913-921, 2014.

27. O'Grady S, Finn SP, Cuffe S, Richard DJ, O'Byrne KJ and Barr MP: The role of DNA repair pathways in cisplatin resistant lung cancer. Cancer Treat Rev 40: 1161-1170, 2014.

28. Qi F, Zhao L, Zhou A, Zhang B, Li A, Wang Z and Han J: The advantages of using traditional Chinese medicine as an adjunctive therapy in the whole course of cancer treatment instead of only terminal stage of cancer. Biosci Trends 9: 16-34, 2015.

29. Zhou J, Zhou T, Jiang M, Wang X, Liu Q, Zhan Z and Zhang X: Research progress on synergistic anti-tumor mechanisms of compounds in traditional Chinese medicine. J Tradit Chin Med 34: 100-105, 2014

30. Liu L and Bian K: Advance in studies on molecular mechanisms of cisplatin resistance and intervention with traditional Chinese medicines. Zhongguo Zhong Yao Za Zhi 39: 3216-3220, 2014 (In Chinese).

31. Kolaczkowska E, Plytycz B, Arnold B, Piccard H and Opdenakker G: Increased cyclooxygenase activity impairs apoptosis of inflammatory neutrophils in mice lacking gelatinase $\mathrm{B} /$ matrix metalloproteinase-9. Immunology 128 (Suppl 1): e262-e274, 2009

32. Woodfin A, Voisin MB, Beyrau M, Colom B, Caille D, Diapouli FM, Nash GB, Chavakis T, Albelda SM, Rainger GE, et al: The junctional adhesion molecule JAM-C regulates polarized transendothelial migration of neutrophils in vivo. Nat Immunol 12: 761-769, 2011.

33. Moog-Lutz C, Cavé-Riant F, Guibal FC, Breau MA, Di Gioia Y, Couraud PO, Cayre YE, Bourdoulous S and Lutz PG: JAML, a novel protein with characteristics of a junctional adhesion molecule, is induced during differentiation of myeloid leukemia cells. Blood 102: 3371-3378, 2003

34. Endo M,Hori M, Ozaki H, Oikawa T and Hanawa T: Rikkunshito, a Kampo medicine, ameliorates post-operative ileus by anti-inflammatory action. J Pharmacol Sci 124: 374-385, 2014

35. Tsubouchi H, Yanagi S, Miura A, Iizuka S, Mogami S, Yamada C, Hattori T and Nakazato M: Rikkunshito ameliorates bleomycin-induced acute lung injury in a ghrelin-independent manner. Am J Physiol Lung Cell Mol Physiol 306: L233-L245, 2014.

36. El Ouriaghli F, Fujiwara H, Melenhorst JJ, Sconocchia G, Hensel $\mathrm{N}$ and Barrett AJ: Neutrophil elastase enzymatically antagonizes the in vitro action of G-CSF: Implications for the regulation of granulopoiesis. Blood 101: 1752-1758, 2003.

37. Loison F, Zhu H, Karatepe K, Kasorn A, Liu P, Ye K, Zhou J, Cao S, Gong H, Jenne DE, et al: Proteinase 3-dependent caspase-3 cleavage modulates neutrophil death and inflammation. J Clin Invest 124: 4445-4458, 2014.

38. Baumann M, Pham CT and Benarafa C: SerpinB1 is critical for neutrophil survival through cell-autonomous inhibition of cathepsin G. Blood 121: 3900-3907, S1-S6, 2013.

39. Parlato M, Souza-Fonseca-Guimaraes F, Philippart F, Misset B; Captain Study Group, Adib-Conquy $\mathrm{M}$ and Cavaillon JM: CD24-triggered caspase-dependent apoptosis via mitochondrial membrane depolarization and reactive oxygen species production of human neutrophils is impaired in sepsis. J Immunol 192: 2449-2459, 2014

40. Wilmes M and Sahl HG: Defensin-based anti-infective strategies. Int J Med Microbiol 304: 93-99, 2014.

41. Holweg A, Schnare M and Gessner A: The bactericidal/permeability-increasing protein (BPI) in the innate defence of the lower airways. Biochem Soc Trans 39: 1045-1050, 2011. 
42. Campbell KS and Hasegawa J: Natural killer cell biology: An update and future directions. J Allergy Clin Immunol 132: 536-544, 2013

43. Jewett A, Tseng HC, Arasteh A, Saadat S, Christensen RE and Cacalano NA: Natural killer cells preferentially target cancer stem cells; role of monocytes in protection against NK cell mediated lysis of cancer stem cells. Curr Drug Deliv 9: 5-16, 2012.

44. Weiland J, Elder A, Forster V, Heidenreich O, Koschmieder S and Vormoor J: CD19: A multifunctional immunological target molecule and its implications for Blineage acute lymphoblastic leukemia. Pediatr Blood Cancer 62: 1144-1148, 2015.

45. Eon Kuek L, Leffler M, Mackay GA and Hulett MD: The MS4A family: Counting past 1, 2 and 3. Immunol Cell Biol 94: 11-23, 2016.

46. Niemann CU and Wiestner A: B-cell receptor signaling as a driver of lymphoma development and evolution. Semin Cancer Biol 23: 410-421, 2013.

47. Salzer U, Chapel HM, Webster AD, Pan-Hammarström Q, Schmitt-Graeff A, Schlesier M, Peter HH, Rockstroh JK, Schneider P, Schäffer AA, et al: Mutations in TNFRSF13B encoding TACI are associated with common variable immunodeficiency in humans. Nat Genet 37: 820-828, 2005.

48. Auchtung TL and Dahl GE: Prolactin mediates photoperiodic immune enhancement: Effects of administration of exogenous prolactin on circulating concentrations, receptor expression, and immune function in steers. Biol Reprod 71: 1913-1918, 2004.

49. Chou FS and Mulloy JC: The thrombopoietin/MPL pathway in hematopoiesis and leukemogenesis. J Cell Biochem 112: 1491-1498, 2011.
50. Biswas A, Ivaskevicius V, Thomas A and Oldenburg J: Coagulation factor XIII deficiency. Diagnosis, prevalence and management of inherited and acquired forms. Hamostaseologie 34: 160-166, 2014.

51. Motaghed M, Al-Hassan FM and Hamid SS: Thymoquinone regulates gene expression levels in the estrogen metabolic and interferon pathways in MCF7 breast cancer cells. Int J Mol Med 33: 8-16, 2014.

52. Gardiner EE and Andrews RK: Platelet receptor expression and shedding: Glycoprotein Ib-IX-V and glycoprotein VI. Transfus Med Rev 28: 56-60, 2014

53. Falanga A, Marchetti M and Russo L: The mechanisms of cancer-associated thrombosis. Thromb Res 135 (Suppl 1): S8-S11, 2015

54. Orozco-Morales M, Soca-Chafre G, Barrios-Bernal P, Hernández-Pedro $\mathrm{N}$ and Arrieta $\mathrm{O}$ : Interplay between cellular and molecular inflammatory mediators in lung cancer. Mediators Inflamm 2016: 3494608, 2016.

55. Buchbinder EI and Desai A: CTLA-4 and PD-1 pathways: Similarities, differences, and implications of their inhibition. Am J Clin Oncol 39: 98-106, 2016. 